SPINELI, André Luiz Pereira; RUSSI, Sofia Covas; ROCHA, Iara Pinheiro; GARCIA, Vinícius Assumpção.

Direitos humanos, educação e ideologias: o movimento "Escola sem partido" como obstáculo à pedagogia histórico-crítica. Dignidade Re-Vista, v.7, n.12, jul 2021

\title{
Direitos humanos, educação e ideologias: o movimento "Escola sem partido" como obstáculo à pedagogia histórico-crítica*
}

Human rights, education and ideologies: the "School without party" movement as an obstacle to historical-critical pedagogy

\section{André Luiz Pereira Spinieli \\ andre.spinieli@unesp.br}

Mestrando em Direito (UNESP).

Especialista em Direitos Humanos

(FACICA)

\section{Sofia Covas Russi}

sofiacovasrussi@gmail.com

Graduanda em Direito (FDF). Bolsista de

Iniciação Científica (FDF)

\section{Iara Pinheiro Rocha \\ iaranroch@gmail.com}

Graduanda em Direito (FDF)

Vinícius Assumpção Garcia

neladhfranca@gmail.com

Graduando em Direito (FDF)

\section{Resumo}

O movimento "Escola Sem Partido" decorre de profundas mudanças sociais e políticas que marcaram o país e impactaram diretamente os sentidos e práticas do campo educacional. Ao encampar o ideal de neutralidade política, ideológica e religiosa, apresenta-se como instrumento útil ao esvaziamento de pedagogias críticas e, consequentemente, da educação como direito humano. Nesse sentido, o artigo objetiva analisar o impacto dessa medida no uso da pedagogia histórico-crítica.

Palavras-chave: Ideologia; direito à educação;

\begin{abstract}
The "School Without Party" movement is the result of profound social and political changes that marked the country and directly impacted the senses and practices of the educational field. In embracing the ideal of political, ideological and religious neutrality, it presents itself as a useful tool for the emptying of critical pedagogies and, consequently, of education as a human
\end{abstract}

\footnotetext{
* Este texto aborda, de forma organizada, as reflexões desenvolvidas sobre educação crítica em direitos humanos e pedagogias alternativas para o ensino do direito (e dos direitos humanos) no âmbito do Núcleo de Estudos LatinoAmericanos em Direitos Humanos (NELADH). Trata-se de uma iniciativa autônoma, sem vínculo institucional em um primeiro momento, que tem por finalidade promover a educação em direitos humanos e atuar tanto na divulgação acadêmico-social de elementos afins à disciplina quanto na promoção material dessas garantias, por meio de ações coordenadas. Em especial, agradecemos aos demais membros do grupo, que, embora não tenham participado diretamente da construção deste trabalho, foram fundamentais para assentar uma tese central sobre o tema discutido.
} 
SPINELI, André Luiz Pereira; RUSSI, Sofia Covas; ROCHA, Iara Pinheiro; GARCIA, Vinícius Assumpção.

Direitos humanos, educação e ideologias: o movimento "Escola sem partido" como obstáculo à pedagogia

right. In this sense, the article aims to analyze the impact of this measure on the use of historicalcritical pedagogy.

Keywords: Ideology; Right to education.

\section{Introdução}

Em meio às profundas mudanças sociais e políticas ocasionadas pelo acirramento das polarizações ideológicas entre direita e esquerda no Brasil, que culminaram no processo de impedimento da ex-presidente Dilma Rousseff, eleita democraticamente à época, no ano de 2016, o movimento "Escola Sem Partido" ganhou espaço e visibilidade junto ao debate público e às agendas políticas neoconservadoras (Scrivano; Bicalho, 2017, p.33). Nessa época, foram apresentados ao Congresso Nacional sucessivos projetos de lei que tinham por finalidade única institucionalizar e articular as reivindicações dos apoiadores do movimento, que estavam concentradas na premissa de que há um "problema gravíssimo que atinge a maioria das escolas e universidades brasileiras: a instrumentalização do ensino para fins político, ideológicos e partidários" (Guilherme; Picoli, 2018, p.3).

Desde cartazes contendo deveres do professor para que o aluno conheça o seu direito de não ser doutrinado a candidatos que assumiram compromisso de apresentar projetos de lei sobre a temática (Scrivano; Bicalho, 2017, p.33), o movimento se autonomeou como representante dos interesses de pais e estudantes contrários ao espectro de doutrinação nas salas de aula (Nunes, 2018, p.10). Assim, por meio da rotulação de professores como doutrinadores ideológicos e da naturalização de práticas de perseguição e violação de direitos fundamentais (Nunes, 2018, p.42), o movimento despontou na realidade nacional como proposta vinculada às racionalidades neoconservadoras que enxergam na educação um campo de disputa para afirmar a luta contra a ideologia (Lira, 2018, p.9-10), inclusive encontrando fundamento no campo do direito internacional dos direitos humanos, na Convenção Americana de Direitos Humanos (CADH), mas ignorando o fato de que, na verdade, se opera uma sobreposição de ideologias.

Ao declarar aversão às práticas educacionais que possuem potencial para apresentar e representar ideologias não dominantes e críticas, que delimitem o modo de agir e estar no mundo do sujeito que é parte do processo de ensino-aprendizagem (Cara, 2016, p.46), o movimento se posiciona a favor de neutralidades políticas, ideológicas e religiosas, o que, consequentemente, inviabiliza diálogos críticos formulados a partir de pedagogias históricocríticas. Formuladas ao longo da década de 1970 no Brasil, as pedagogias histórico-críticas 
SPINELI, André Luiz Pereira; RUSSI, Sofia Covas; ROCHA, Iara Pinheiro; GARCIA, Vinícius Assumpção. Direitos humanos, educação e ideologias: o movimento "Escola sem partido" como obstáculo à pedagogia

encontram seu fundamento no materialismo histórico-dialético de Marx e Gramsci, cuja base recupera a necessidade de construir sujeitos para a dimensão prática da realidade material, ascender à teoria e, ao retornar à prática, compreendê-la como ação transformadora, a práxis social (Severino, 1986, p.100; Nunes, 2018, p.84-86). O formato de educação que não tem como característica a construção de consciências críticas e reflexivas deixa de cumprir com seu papel de desnudamento da realidade (Severino, 1986, p.97; Possamai, 2014, p.53).

A partir desse panorama, este trabalho tem como objetivo analisar o impacto negativo do movimento "Escola Sem Partido" na construção de pedagogias histórico-críticas, visualizando o esvaziamento desses mecanismos e a formulação de perspectivas educacionais acríticas e destoadas da realidade histórico-material do sujeito inserido no processo de ensinoaprendizagem. $\mathrm{O}$ artigo avança sobre a ideia de que o movimento em questão representa um instrumento de violação à educação como direito humano, sobretudo por almejar a retirada de doutrinações ideológicas nos campos educacionais, inviabilizando a pluralidade de ideias. Metodologicamente, o escrito se fundamenta na pesquisa descritiva documental, cujo desenvolvimento é realizado de acordo com a abordagem literária sobre o movimento "Escola Sem Partido", a pedagogia histórico-crítica e a educação como direito humano.

Para a concretização dos objetivos traçados, o artigo se divide em três capítulos. No primeiro, aproxima-se ao conceito e fundamentos da pedagogia histórico-crítica, buscando identificar as bases de sua criticidade e como se materializa na condição de instrumento para a cidadania. No segundo, analisa-se o movimento "Escola Sem Partido" a partir de seus ideais e desdobramentos em solo brasileiro. No terceiro, busca-se afirmar como o movimento pode servir de obstáculo à construção de pedagogias histórico-críticas e, assim, retirar o potencial ideológico da educação.

\section{Pedagogias histórico-críticas como fundamentos para a cidadania consciente}

No final da década de 1970, a construção da pedagogia histórico-crítica veio à tona como parcela de um movimento de rígidas transformações educacionais, sociais e culturais, que rapidamente se alastraram para o âmbito internacional e demarcaram seu propósito de desconstruir a pedagogia tradicional por meio da negação de seu caráter reprodutor, desvinculado da história e não questionador de práticas socialmente consolidadas (Saviani, 2005, p.131; Possamai, 2014, p.53). Apoiada em materialismos histórico-dialéticos de matriz marxiana e gramsciana, a ideia central da pedagogia histórico-crítica é fazer com que o aluno 
SPINELI, André Luiz Pereira; RUSSI, Sofia Covas; ROCHA, Iara Pinheiro; GARCIA, Vinícius Assumpção. Direitos humanos, educação e ideologias: o movimento "Escola sem partido" como obstáculo à pedagogia

se construa como protagonista de seu meio social, erguido a partir de uma concepção consciente de cidadania, de modo que a escola figure tanto na condição de espaço para a decantação e continuidade de suas experiências anteriores (Nunes, 2018, p.85) quanto como campo de formação para a transformação social.

A trajetória epistemológica da pedagogia histórico-crítica se estrutura em cinco fases (Oliveira, 2007, p. 44). A primeira diz respeito à prática social inicial, instante em que educador e educando tomam como ponto de partida conhecimentos já adquiridos, ainda que em níveis diferenciados sobre o mesmo tema. A segunda consiste na problematização, que objetiva explicar os principais problemas inseridos pelo viés prático, cujo desenvolvimento se dá por meio da realização de discussões que retomam a problemática a partir de aspectos socioeconômicos, políticos, históricos, culturais e éticos. A terceira é a instrumentalização, pela qual o educador aplica o conhecimento científico sobre as inquietações de ordem prática. O quarto ponto recupera a ideia de catarse, que consiste na exposição da síntese alcançada pelo educando. A quinta dimensão é a prática social final, que representa o novo nível de desenvolvimento do educando, a partir do qual assume propostas de ação para a transformação da realidade material (Gasparin, 2013, p.143).

Por isso, pode-se dizer que a trajetória epistemológica da pedagogia histórico-crítica (re)valoriza a cidadania em suas múltiplas vertentes e permite o debate consciente sobre temáticas que estão enquadradas na realidade material do educando, possibilitando sua conformação como protagonista social (Nunes, 2018, p.86). Ao adotar ideologias libertadoras como estratégia discursiva para reconsiderar o papel da educação na construção da cidadania, esse modelo pedagógico "valoriza a escola e se preocupa com os interesses dos trabalhadores" (Oliveira, 2007, p.44). Nesse sentido, ainda que a escola possua uma função essencialmente educativa e vinculada às questões puramente pedagógicas, na sociedade de classes em que a instrução crítica da população vai de encontro aos interesses das classes hegemônica, essa perspectiva enxerga que há um movimento de desvalorização dos espaços educacionais, a fim de reduzir sua participação e impacto nos processos transformativos da sociedade (Saviani, 2005, p.99).

Como chave de leitura para a cidadania, a pedagogia histórico-crítica possibilita que "novas gerações incorporem os elementos herdados de modo que se tornem agentes ativos no processo de desenvolvimento e transformação das relações sociais" (Saviani, 2005, p. 143). A partir da assimilação do conceito marxiano de ideologia e da análise dos acontecimentos 
SPINELI, André Luiz Pereira; RUSSI, Sofia Covas; ROCHA, Iara Pinheiro; GARCIA, Vinícius Assumpção.

Direitos humanos, educação e ideologias: o movimento "Escola sem partido" como obstáculo à pedagogia

históricos como elementos úteis à descoberta de leis gerais da evolução social (Oliveira, 2007, p.47), essa concepção pedagógica busca viabilizar o domínio da cultura para grupos não hegemônicos, fazendo com que se tornem legítimos reivindicantes de seus direitos humanos (Saviani, 2005, p.55). Assim, é possível afirmar que o papel fundamental da pedagogia histórico-crítica é redimensionar as balizas da cidadania para abarcar a possibilidade de libertação dos sujeitos dominados e inseri-los no domínio da cultura ${ }^{1}$ (Saviani, 2005, p.55).

Os direitos de cidadania são direitos humanos que se constituem como conquista comum da humanidade e materialização da democracia (Corrêa, 2006, p.214). Para além da detenção dos meios de produção, revelar-se como cidadão crítico em uma sociedade de classes significa ter consciência de seu lugar social e de que se constitui como sujeito de direitos e deveres (Pires; Cavichioli, 2009, p.4). Para a construção desse sentido de cidadania, a educação possui função determinante: trata-se de consolidar uma pedagogia que, partindo-se da relação entre pedagogia e "prática social histórica e concreta, (...) propicia a crítica dos mecanismos e imposições resultantes da organização da sociedade em classes sociais antagônicas" (Libâneo, 1996, p.12). Se o movimento "Escola Sem Partido" representa o esvaziamento da pluralidade de ideias por meio de um artifício retórico calcado na ideologia, a pedagogia histórico-crítica surge como alternativa à transformação da educação em campo de ideias homogêneas.

\section{"Escola Sem Partido": gênese e estratégias político-educacionais de combate às ideologias não hegemônicas}

As disputas sociais sobre os sentidos da educação contemporânea têm como característica a rotulação da instituição escolar como espaço de divulgação de ideologias contrárias aos interesses hegemônicos, que atacam diretamente valores e concepções de matriz liberal, conservadora e fundamentalista religiosa (Katz; Mutz, 2017, p.186). Fundado a partir da missão de extirpar a doutrinação ideológica das escolas por meio de estratégias que vão desde a denúncia do fracasso educacional até a construção da imagem do professor como doutrinador, o movimento "Escola Sem Partido" surgiu no ano de 2004 como uma criação de Miguel Nagib, posicionando-se nesse embate como contraproposta a um cenário de falência educacional

\footnotetext{
1 "O domínio da cultura constitui instrumento indispensável para a participação política das massas. Se os membros das camadas populares não dominam os conteúdos culturais, eles não podem fazer valer os seus interesses, porque ficam desarmados contra os dominadores, que se servem exatamente desses conteúdos culturais para legitimar e consolidar a sua dominação. O dominado não se liberta se ele não vier a dominar aquilo que os dominantes dominam. Então dominar o que os dominantes dominam é condição de libertação" (Saviani, 2005, p. 55).
} 
SPINELI, André Luiz Pereira; RUSSI, Sofia Covas; ROCHA, Iara Pinheiro; GARCIA, Vinícius Assumpção. Direitos humanos, educação e ideologias: o movimento "Escola sem partido" como obstáculo à pedagogia

denunciado em virtude da divulgação de ideologias vinculadas à esquerda política (Katz; Mutz, 2017, p.186).

Embora tenha se destacado em 2016, no período que coincidiu com o processo de impedimento de Dilma Rousseff (Scrivano; Bicalho, 2017, p.33), o movimento se aparelhou a partir da emergência governamental do Partido dos Trabalhadores (PT) em 2004 (Katz; Mutz, 2017, p.186). Na gênese das discussões sobre o papel da ideologia produzida pelos partidos políticos da esquerda brasileira no âmbito das escolas e universidades, o movimento "Escola Sem Partido" se institucionalizou inicialmente em Alagoas, onde se tornou lei estadual sob o nome de "Lei da Escola Livre" (Scrivano; Bicalho, 2017, p.33). Concomitantemente, alastrouse para o Ministério da Educação, que recebeu representantes do movimento para trabalhar o tema (Scrivano; Bicalho, 2017, p.33).

Por meio do combate à divulgação de ideologias não hegemônicas em escolas e universidades, especialmente no campo da educação básica pública, o movimento "Escola Sem Partido" se desenvolveu por meio de estratégias que podem ser divididas em três etapas. $\mathrm{Na}$ primeira, trata-se de uma construção reprodutiva, por meio da qual os textos e teses que sustentam a ideologia do movimento são copiados para a formatação de uma identidade própria. Na segunda, passa-se à midiatização e repercussão na internet e nos debates judiciais, sobretudo nos casos que envolviam diretamente as denúncias feitas por e contra o movimento. Na terceira fase, a marca é justamente a tentativa de institucionalização do projeto por meio da aprovação de propostas legislativas, o que, como consequência, impulsiona a continuidade midiática do movimento (Katz; Mutz, 2017, p.186). Em realidade, a escolha do objeto a ser perseguido pelo movimento é decorrente das "crescentes expansões do pensamento neoliberal ou, até mesmo, a politização de grupos religiosos (...) ao lado do próprio sucesso acadêmico do marxismo (juntamente com as contínuas vitórias políticas do PT)" (Katz; Mutz, 2017, p.186-187).

Ao se posicionar como uma "iniciativa conjunta de estudantes e pais preocupados com o grau de contaminação político-ideológica das escolas brasileiras, em todos os níveis: do ensino básico ao superior" (Algebaile, 2017, p.64), o movimento "Escola Sem Partido" sugere indiretamente o avanço de pautas conservadoras no campo da política educacional brasileira (Nunes, 2018, p.32). Para além de um agir substitutivo de ideologias, que enfraquece ou extirpa aquelas de matriz não hegemônica para encampar valores de natureza conservadora, especialmente vinculados à rejeição do debate sobre a ideologia de gênero nos diferentes espaços educacionais, os adeptos desse movimento se colocam como negacionistas do acesso 
SPINELI, André Luiz Pereira; RUSSI, Sofia Covas; ROCHA, Iara Pinheiro; GARCIA, Vinícius Assumpção. Direitos humanos, educação e ideologias: o movimento "Escola sem partido" como obstáculo à pedagogia

à educação como possibilidade de exercício da crítica (Nunes, 2018, p.32). Mais que isso, ao trabalhar com pautas associadas à proposta neoliberal de educação, responsáveis por transformá-la em mercadoria (Dardot; Laval, 2016, p.16), a tendência é produzir o ato de educar como mera transmissão de conteúdo (Nunes, 2018, p.32).

Como produto direto das relações socioeconômicas construídas sob a égide do neoliberalismo e da assimilação social de posições conservadoras, pode-se dizer que o movimento "Escola Sem Partido" se estrutura a partir do esvaziamento de ideologias não hegemônicas no campo da educação e, consequentemente, aproxima-se dos aparelhos de repressão estatal para aplicá-los também ao espaço escolar (Nunes, 2018, p.34). Nesse viés, um dos principais indicativos da potencialidade lesiva do movimento em questão está no fato de que, se a maior parte dos estudantes se encontra matriculada na rede pública de ensino brasileira (Nunes, 2018, p.34), a afirmação de mecanismos conservadores no âmbito educacional representa o controle das massas subalternas por grupos hegemônicos (Gawryszewski; Motta, 2017, p.25). Para que o movimento "Escola Sem Partido" tenha voz na sociedade contemporânea, é indispensável reproduzir a educação não como espaço de transformação, mas sim de controle (Nunes, 2018, p.34).

Erguido sobre bases desorganizadas e confusão, que não permitem a identificação com clareza de quem são exatamente seus integrantes ou mesmo seus porta-vozes, senão aqueles que se autonomeiam coordenador e vice-presidente, Miguel Nagib e Bráulio Porto, o movimento "Escola Sem Partido" oscila seu objeto de combate na educação brasileira, identificando o inimigo a ser extirpado ora na ideologia de gênero, ora na doutrinação marxista (Miguel, 2016, p.595). De fato, tais pautas decorrem tanto do sucesso das abordagens marxistas às questões acadêmicas (Katz; Mutz, 2017, p.186-187) quanto dos receios sobre a discussão dos papéis de gênero articulados por grupos religiosos conservadores (Miguel, 2016, p.595596).

Como proposta de matriz liberal e conservadora, o movimento "Escola Sem Partido" se insere no cenário político-educacional como operador de transformações ideológicas: uma mudança que visa retirar ideologias associadas à esquerda política brasileira das escolas e universidades e inserir pautas conservadoras, transferindo discussões sobre gênero, por exemplo, para o campo da moralidade, e não mais do espectro político-social (Miguel, 2016, p.596). 
SPINELI, André Luiz Pereira; RUSSI, Sofia Covas; ROCHA, Iara Pinheiro; GARCIA, Vinícius Assumpção. Direitos humanos, educação e ideologias: o movimento "Escola sem partido" como obstáculo à pedagogia

\section{Educação entre ideologias: o movimento "Escola Sem Partido" como obstáculo à pedagogia histórico-crítica}

Reconhecer que a educação está entre colchetes no embate de polarizações ideológicopolíticas significa levar em consideração o movimento "Escola Sem Partido" como espécie de lei da mordaça, cuja base de atuação perpassa tanto pela criminalização da docência (Miguel, 2016, p 614) quanto pela condenação do pensamento crítico ou, ao menos, de reflexões que empreguem perspectivas histórico-críticas. A eliminação das liberdades de expressão e de cátedra dos professores, provocando a transformação do docente em doutrinador, representa uma das linhas de ação do movimento, cujo pensamento se alinha à ideia de que, em sala de aula, cabe ao professor somente transmitir conteúdo, nada mais (Miguel, 2016, p.614). Por isso, a pedagogia histórico-crítica estimula o debate a partir da problematização de temas sociais, que são resolvidos na dialética entre o repertório histórico do aluno e a introdução do conhecimento científico pelo professor (Saviani, 2005, p.55).

Ao adotar como ponto de partida a prática social, a pedagogia histórico-crítica revela que a educação possui uma dimensão que não transforma a realidade de modo direto e imediato, mas indireta e mediatamente (Oliveira, 2007, p.45), uma vez que a assimilação do problema trabalhado em sala de aula decorre de um processo com alterações qualitativas de entendimento. Assim, enquanto a pedagogia histórico-crítica concebe educação como "uma atividade mediadora no seio da prática social global" (Saviani, 1980, p.129), a estruturação do movimento "Escola Sem Partido" tem como efeito a redução do potencial crítico dos debates desenvolvidos em sala de aula e, para além desse aspecto, limita a exposição da pluralidade de ideias, transformando a escola em espaço de homogeneidades educacionais (Nunes, 2018, p.86). Logo, torna-se estéril a possibilidade de enfrentar questões sociais, políticas e históricas e problematizá-las.

Na verdade, o movimento "Escola Sem Partido" busca se promover social e politicamente a partir de uma educação considerada neutra e livre de quaisquer ideologias, sobretudo aquelas de matriz marxista ou de gênero (Katz; Mutz, 2017, p.198), proibindo que o professor discuta temas que toquem em problemas de religião, desigualdades sociais, ideologias não hegemônicas ou mesmo as diferenças entre gêneros (Nunes, 2018, p.87). Em contrariedade a essa posição, a pedagogia histórico-crítica nega a existência de uma neutralidade educacional, uma vez que indica se tratar de um mito forjado pelo raciocínio positivista (Saviani, 2005, p.8). De fato, o modo de pensar criticamente por meio de elementos históricos desmantelou o 
SPINELI, André Luiz Pereira; RUSSI, Sofia Covas; ROCHA, Iara Pinheiro; GARCIA, Vinícius Assumpção. Direitos humanos, educação e ideologias: o movimento "Escola sem partido" como obstáculo à pedagogia

pensamento positivista e tornou possível "negar a neutralidade e, ao mesmo tempo, afirmar a objetividade" (Saviani, 2005, p.8). Em outros termos, o movimento "Escola Sem Partido" inviabiliza o processo de aprendizagem crítica.

Uma das dimensões possíveis do direito humano à educação consiste na afirmação da liberdade de manifestação de diferentes ideologias, que coexistem no espaço escolar e formam o princípio democrático (Trindade, 2007, p.29). Em realidade, o desenvolvimento crítico do educando apenas se faz possível por meio do "confronto de ideias, concepções, sistemas de ensino (...) com metodologias e ideologias diferentes, sempre proibindo a existência de um monopólio na área da educação" (Trindade, 2007, p.29). Nesse sentido, o movimento "Escola Sem Partido", ao objetivar a retirada de ideologias não hegemônicas das escolas, não apenas (re)afirma seu lugar na luta neoliberal pelos espaços educacionais, mas também abre mão do dever de formação crítica do sujeito para a cidadania consciente por se tratar de um elemento político (Nunes, 2018, p.88-89). Assim, propõe-se a idealização do professor como ator social que deve levar seus educandos para distante da política e aproximá-los da moralidade.

Além de mecanismo formativo para a cidadania, a educação enquanto direito humano representa a possibilidade material de pensar a realidade por meio de expressões históricas adequadas ao campo em que o ator social está inserido (Nunes, 2018, p.88-89). O movimento "Escola Sem Partido" inviabiliza a pedagogia histórico-crítica ao propor indiretamente a formação de educandos conformados, repetitivos, adequados aos arranjos institucionais e sociais vigentes e não voltados à transformação dos rumos da história, senão à (re)produção desse modelo de sociedade, favorecendo grupos hegemônicos em detrimento de grupos subjugados (Nunes, 2018, p.88-89). Embora se apresente como movimento democrático, que busca livrar a sociedade brasileira e os educandos, do nível básico ao superior, dos malefícios de ideologias que colocam em risco valores morais, trata-se, na verdade, de um movimento articulado por partidos políticos conservadores que se engajaram em um combate para a manutenção da organização político-social.

Entre a negação da pluralidade de ideias no espaço escolar e o uso da luta contras as ideologias vinculadas à esquerda brasileira como espécie de cortina de fumaça para ocultar os reais propósitos de manutenção dos arranjos sociais, o movimento "Escola Sem Partido" torna a prática dos direitos humanos, sobretudo dos direitos de acesso à educação crítica e transformadora por parte de educandos e da liberdade de expressão pelos educadores, mero artifício retórico, uma vez que "ter um direito é se tornar irresponsável" (Miguel, 2016, p.614). 
SPINELI, André Luiz Pereira; RUSSI, Sofia Covas; ROCHA, Iara Pinheiro; GARCIA, Vinícius Assumpção. Direitos humanos, educação e ideologias: o movimento "Escola sem partido" como obstáculo à pedagogia

A construção da neutralidade como argumento central para a ação material do movimento projeta a educação como instrumento incapaz de intervir eficazmente para a transformação da realidade objetiva, fazendo com que se torne "cúmplice das injustiças e das violências que nela ocorrem" (Miguel, 2016, p.615). Como violação do direito humano à educação de qualidade, as propostas do movimento se afastam de pedagogias histórico-críticas, inviabilizando sua aplicação por se tratarem de mecanismos ideologicamente associados à esquerda política, e se aproximam da neutralização do espaço escolar, "para que a autoridade que os pais exercem sobre os filhos possa ser absoluta" (Miguel, 2016, p.617).

\section{Considerações finais}

A finalidade deste trabalho foi explorar os impactos do movimento "Escola Sem Partido" no emprego educacional da pedagogia histórico-crítica, tomando como ponto de partida a ideia de que essa construção típica do conservadorismo brasileiro adota como ideal a neutralidade política, ideológica e religiosa no campo educacional, ofertando elementos suficientes para o esvaziamento valorativo das pedagogias críticas e o desestímulo à sua utilização como metodologia-guia. O movimento em questão surgiu como resposta direta à ascensão política do PT no ano de 2004, ainda que o período de maior desenvolvimento tenha sido o ano de 2016, após o término do processo de impedimento de Dilma Rousseff, instante que coincide com o assentamento público dos ideais da escola livre de ideologias.

O modelo de pedagogia histórico-crítica tem por objetivo fazer com que o educando se torne sujeito protagonista em seu meio social, aplicando nas assimetrias da realidade material os elementos aprendidos (e apreendidos) em sala de aula, responsáveis pela formação cidadã consciente desses indivíduos. Mais que isso, nessa concepção, os espaços educacionais funcionam como arenas de decantação e continuidade de experiências adquiridas anteriormente pelo aluno. Ao inviabilizar a pedagogia histórico-crítica por meio da exclusão de ideologias não hegemônicas da política educacional brasileira, o movimento "Escola Sem Partido" se coloca na contramão da cidadania consciente e da educação crítica e transformadora enquanto direito humano. Ao contrário desses elementos, o movimento permite indiretamente a formação de sujeitos conformados e adequados aos arranjos político-sociais em vigência, a fim de servirem não aos interesses dos grupos subjugados, mas somente dos grupos hegemônicos.

Portanto, pode-se concluir que o impacto do movimento "Escola Sem Partido" no emprego da pedagogia histórico-crítica perpassa não apenas o esvaziamento das ideologias não 
SPINELI, André Luiz Pereira; RUSSI, Sofia Covas; ROCHA, Iara Pinheiro; GARCIA, Vinícius Assumpção. Direitos humanos, educação e ideologias: o movimento "Escola sem partido" como obstáculo à pedagogia

dominantes no campo educacional, que incluem as vertentes críticas, mas também a afirmação da necessidade de substituição desses mecanismos por novas ideologias. Significa dizer que o movimento, no afã de buscar a neutralidade ideológica dos espaços e práticas educacionais, termina por se perder em seu próprio objeto de luta e ofertar, na verdade, a substituição de ideologias não hegemônicas por ideologias vinculadas aos grupos dominantes. Trata-se de um movimento hierarquicamente desorganizado e cujo objeto e ideais não são delimitados, pendendo tanto para o campo da "doutrinação marxista" quanto para a "ideologia de gênero", que não permite o emprego da pedagogia histórico-crítica e, assim, inviabiliza práticas sociais conscientes da função transformadora da cidadania e dos direitos humanos. 
SPINELI, André Luiz Pereira; RUSSI, Sofia Covas; ROCHA, Iara Pinheiro; GARCIA, Vinícius Assumpção. Direitos humanos, educação e ideologias: o movimento "Escola sem partido" como obstáculo à pedagogia

\section{Referências bibliográficas}

ALGEBAILE, Eveline. Escola sem Partido: o que é, como age, para que serve. In: FRIGOTTO, Gaudêncio (Org.). Escola "sem" Partido: esfinge que ameaça a educação e a sociedade brasileira. Rio de Janeiro: UERJ, 2017.

CARA, Daniel. O programa "Escola sem Partido" quer uma escola sem educação. In: SOUZA, Ana Lúcia Silva et al. (Orgs.). A ideologia do movimento Escola sem Partido: 20 autores desmontam o discurso. São Paulo: Ação Educativa, 2016.

CORRÊA, Darcísio. A construção da cidadania: reflexões histórico-políticas. Ijuí: Unijuí, 2006.

DARDOT, Christian; LAVAL, Pierre. A nova razão do mundo: ensaio sobre a sociedade neoliberal. São Paulo: Boitempo, 2016.

GASPARIN, João Luiz. Uma didática para a pedagogia histórico-crítica. 5.ed. Campinas: Autores Associados, 2013.

GAWRYSZEWSKI, Bruno; MOTTA, Vânia. A ofensiva conservadora-liberal na educação: elementos para uma análise da conjuntura contemporânea. Trabalho Necessário, Rio de Janeiro, v.15, n.26, p.6-29, 2018.

GUILHERME, Alexandre Anselmo; PICOLI, Bruno Antônio. Escola sem Partido - elementos totalitários em uma democracia moderna: uma reflexão a partir de Arendt. Revista Brasileira de Educação, v.23, n.1, p.1-23, 2018.

KATZ, Elvis Patrik; MUTZ, Andresa Silva da Costa. Escola sem Partido: produção de sentidos e disputas em torno do papel da escola pública no Brasil. Educação Temática Digital, Campinas, v.19, n.1, p.184-205, jan/mar 2017.

LIBÂNEO, José Carlos. Democratização da escola pública: a pedagogia crítico-social dos conteúdos. 14.ed. São Paulo: Loyola, 1996.

LIRA, Luciano Paz de. Os atravessamentos ideológicos do movimento Escola sem Partido. 128 f. Dissertação (Mestrado em Linguística Aplicada) - Programa de Pós-Graduação em Linguística Aplicada, Universidade de Taubaté, Taubaté, 2018.

MIGUEL, Luís Felipe. Da "doutrinação marxista" à "ideologia de gênero": Escola Sem Partido e as leis da mordaça no parlamento brasileiro. Direito e Práxis, Rio de Janeiro, v.7, n.15, p.590$621,2016$.

NUNES, Sílvia Ávila. Escola sem Partido sob a crítica de uma perspectiva democrática de educação. 166 f. Dissertação (Mestrado em Educação) - Programa de Pós-Graduação em Educação, Universidade do Sul de Santa Catarina, Tubarão, 2018. 
SPINELI, André Luiz Pereira; RUSSI, Sofia Covas; ROCHA, Iara Pinheiro; GARCIA, Vinícius Assumpção. Direitos humanos, educação e ideologias: o movimento "Escola sem partido" como obstáculo à pedagogia

OLIVEIRA, Regina Maria Horta Barbosa de. A pedagogia histórico-crítica: das propostas pedagógicas à sua implementação. 168 f. Dissertação (Mestrado em Educação) - Centro de Ciências Humanas e Sociais, Universidade Federal de Mato Grosso do Sul, Campo Grande, 2007.

PIRES, Nara Suzana Stainr; CAVICHIOLI, Rossana Braga Pires. Cidadania e educação conscientes. Revista Eletrônica do Curso de Direito da UFSM, v.4, n.1, p.1-12, 2009.

POSSAMAI, Clarívia Fontana. A função social da escola, o papel do professor e a relevância do conhecimento científico na pedagogia histórico-crítica. $110 \mathrm{f}$. Dissertação (Mestrado em Educação) - Programa de Pós-Graduação em Educação, Universidade do Sul de Santa Catarina, Tubarão, 2014.

SAVIANI, Dermeval. Educação: do senso comum à consciência filosófica. São Paulo: Cortez, 1980.

SAVIANI, Dermeval. Pedagogia histórico-crítica: primeiras aproximações. 9.ed. Campinas: Autores Associados, 2005.

SCRIVANO, Isabel; BICALHO, Pedro Paulo Gastalho de. Escola "sem" Partido: enfrentamentos e desafios para a formação em psicologia. Psicologia: Ensino e Formação, v.8, n.1, p.32-47, jan/jun 2017.

SEVERINO, Antônio Joaquim. Educação, ideologia e contra-ideologia. São Paulo: EPU, 1986.

TRINDADE, André (Coord.). Direito educacional: sob uma ótica sistêmica. Curitiba: Juruá, 2007. 